\title{
Respuesta a tratamiento hormonal en cáncer de próstata diseminado
}

\author{
P. Serrano Frago, Má.J. Gil Sanz, M. Allué López, Á. García de Jalón Martínez, \\ D. Pascual Regueiro, L.Á. Rioja Sanz
}

Servicio de Urología de Hospital Universitario Miguel Servet. Zaragoza.

Actas Urol Esp 2005; 29 (6): 616

$\mathrm{V}$ arón de 66 años diagnosticado de adenocarcinoma de próstata bien diferenciado con PSA: $12.320 \mathrm{ng} / \mathrm{ml}$, en el estudio de extensión aparecen grandes adenopatías iliacas, periprostáticas que desplazan la vejiga, retroperitoneales y retrocrurales (Fig. 1). Se administra tratamiento hormonal (bloqueo androgénico completo con flutamida y análogo trimestral) y a los 8 meses se evidencia respuesta espectacular con reducción de las adenopatías iliacas y desaparición de las retroperitoneales (Fig. 2).

Dra. P. Serrano Frago

C/ Lapuyade 19; 1ํ A 50007 Zaragoza

e-mail: pserranof@comz.org
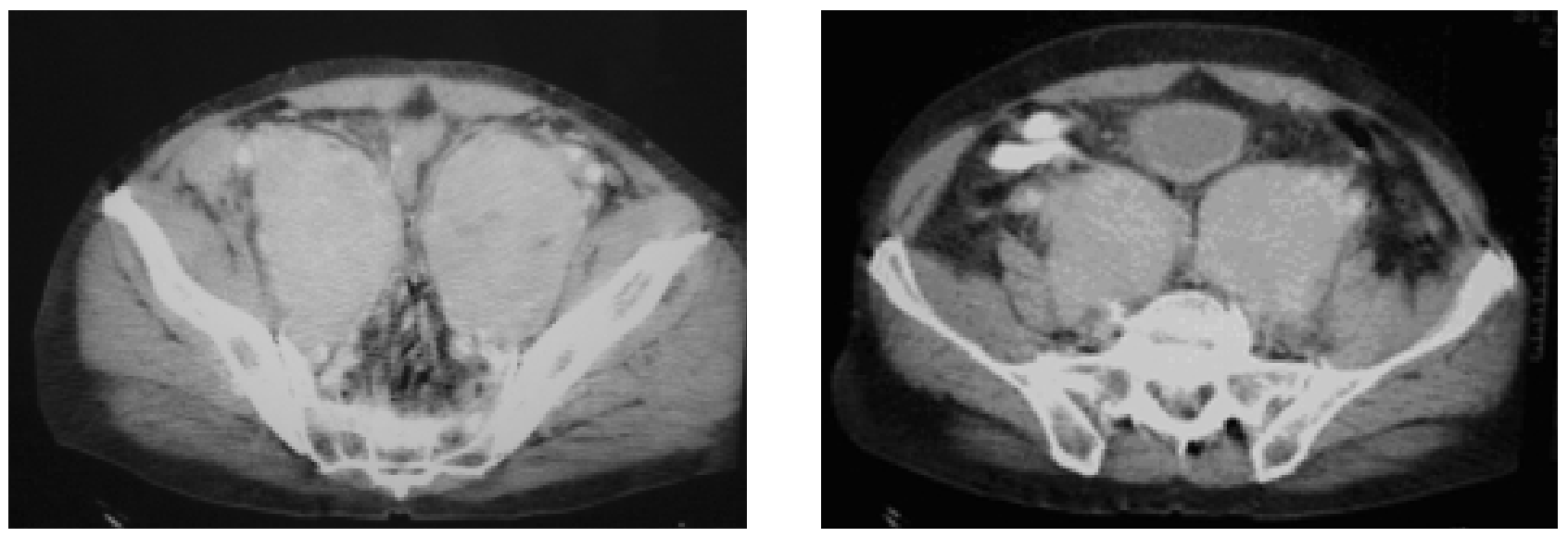

FIGURA 1. Adenopatias iliacas de aproximadamente $7 \mathrm{~cm}$ de de diámetro y periprostáticas que desplazan vejiga.

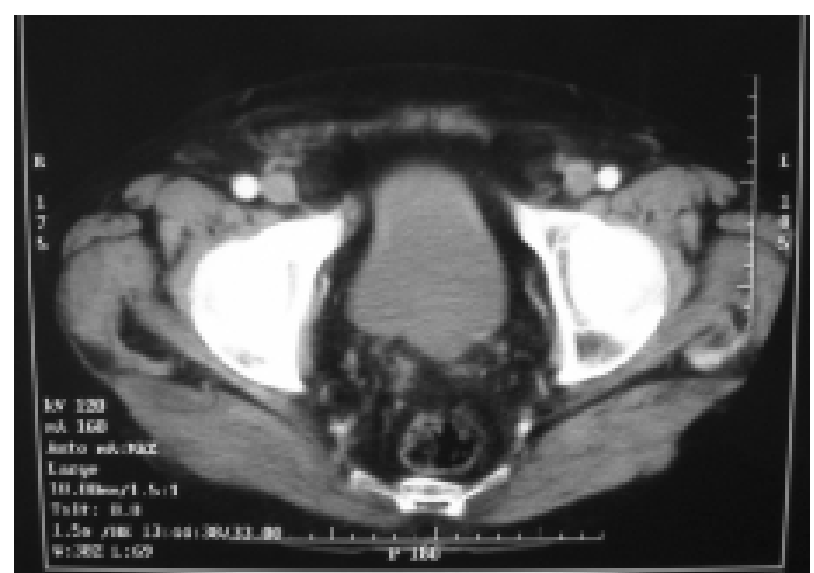

FIGURA 2. Desaparición de adenopatias periprostáticas con vejiga en posición normal. 